\title{
RMetS
}

Royal Meteorological Society

\section{The diurnal cycle of precipitation over the Maritime Continent in a high-resolution atmospheric model}

\author{
Barnaby S. Love, ${ }^{a \star}$ Adrian J. Matthews ${ }^{\mathrm{ab}}$ and Grenville M. S. Lister ${ }^{\mathrm{c}}$ \\ ${ }^{a}$ School of Environmental Sciences, University of East Anglia, Norwich, UK \\ ${ }^{\mathrm{b}}$ School of Mathematics, University of East Anglia, Norwich, UK \\ ${ }^{\mathrm{C}}$ National Centre for Atmospheric Science, University of Reading, UK \\ ${ }^{\star}$ Correspondence to: B. S. Love, School of Environmental Sciences, University of East Anglia, Norwich NR4 7TJ, UK. \\ E-mail: b.love@uea.ac.uk
}

\begin{abstract}
Climate models can exhibit systematic errors in their mean precipitation over the Maritime Continent of the Indonesian archipelago at the heart of the tropical warm pool. These can often be traced back to an erroneous simulation of the diurnal cycle, and can lead to errors in global climate, through planetary wave propagation. Here, we examine the simulation of the diurnal cycle over the Maritime Continent in a series of high-resolution integrations of the UK Met Office atmospheric model, with horizontal resolutions of 40 and $12 \mathrm{~km}$ (where the convection is parametrised) and $4 \mathrm{~km}$ (where the convection is explicitly resolved), as part of the Cascade project. In these models, the vertical heating profile over the islands changes from a convective profile with a mid-tropospheric maximum in the early afternoon to a more stratiform profile with upper-tropospheric heating and mid-tropospheric cooling later. The convective heating profile forces a first internal mode gravity wave that propagates rapidly offshore; the deep warm anomalies behind its downwelling wavefront suppress convection offshore during early afternoon. The stratiform heating profile forces a gravity wave with a higher-order vertical mode that propagates slowly offshore later in the afternoon. This mode has a negative, destabilising temperature anomaly in the mid-troposphere. Together with the convergence zone between the wave fronts of the two modes, favourable conditions are created for offshore convection. In the $4 \mathrm{~km}$ explicit convection model, the offshore convection responds strongly to this gravity wave forcing, in agreement with observations, supporting a gravity wave-convection paradigm for the diurnal cycle over the Maritime Continent. However, the convective response in the lower-resolution models is much less coherent, leading to errors in the diurnal cycle and mean precipitation. Hence, to improve climate model simulations, sensitivity to gravity wave forcing should be a factor in future convective parametrisation schemes. Copyright (C) 2011 Royal Meteorological Society
\end{abstract}

Key Words: $\quad$ gravity wave; sea breeze; Cascade project; Unified Model

Received 1 November 2010; Revised 29 January 2011; Accepted 14 February 2011; Published online in Wiley Online Library 20 May 2011

Citation: Love BS, Matthews AJ, Lister GMS. 2011. The diurnal cycle of precipitation over the Maritime Continent in a high-resolution atmospheric model. Q. J. R. Meteorol. Soc. 137: 934-947. DOI:10.1002/qj.809

\section{Introduction}

The high sea surface temperatures (SSTs) of the tropical warm pool (Indian Ocean to western Pacific) support the largest region of high precipitation in the Tropics. The Maritime Continent of Indonesia and neighbouring countries lies at the heart of the warm pool. It comprises many islands surrounded by shallow seas. The size of these islands range from over $1000 \mathrm{~km}$ (Sumatra, Java, Borneo, New Guinea; Figure 1) down to less than $1 \mathrm{~km}$. The complex shape and orientation of the island coastlines are accentuated by significant topography, with extensive 
mountain ridges over $2000 \mathrm{~m}$ above sea level, with individual peaks over $4000 \mathrm{~m}$. Not surprisingly, precipitation varies considerably across the Maritime Continent. Locally, the mean precipitation rate exceeds $10 \mathrm{~mm} \mathrm{day}^{-1}$ over large areas (e.g. Ichikawa and Yasunari, 2006), and forms a significant part of the regional monsoon circulation.

Precipitation over the Maritime Continent also affects circulation and climate globally. Latent heat release within the precipitating clouds drives equatorial waves that affect circulation over the entire Tropics. The divergent outflow associated with the heat release also interacts meridionally with the mean subtropical jet structures, leading to a Rossby wave source and planetary wave propagation into the extratropics (Jin and Hoskins, 1995).

However, precipitation over the Maritime Continent is generally poorly simulated in global climate or general circulation models (GCMs). Simulations with the UK Met Office climate model (HadAM3, the atmospheric component of the Met Office IPCC Third Assessment Report contribution; Houghton et al., 2001) showed a dry bias of over $2 \mathrm{~mm} \mathrm{day}^{-1}$ over the Maritime Continent (Neale and Slingo, 2003). The resulting erroneous latent heating anomalies then drove an anomalous equatorial wave response that led to a wet bias of over $2 \mathrm{~mm} \mathrm{day}^{-1}$, to the west over the western Indian Ocean and to the east over the western Pacific. These errors in the tropical heating field then led to global errors via planetary wave propagation.

The time-mean precipitation over the Maritime Continent (and its global response) is just the average of all the precipitating weather systems in the region. This is dominated by the diurnal cycle. The advent of recent highresolution satellite data, particularly from the precipitation radar on the Tropical Rainfall Measuring Mission (TRMM), has enabled the structure of the diurnal cycle of tropical precipitation to be studied in unprecedented detail. Over the ocean, the diurnal cycle of precipitation is generally weak and peaks in the early morning (Nesbitt and Zipser, 2003). Over land, it is stronger and peaks in the evening. Additionally, the complex topography of the Maritime Continent leads to strong land-sea breeze circulations, with integral convection and precipitation, over the larger islands (Yang and Slingo, 2001), such as Sumatra (Mori et al., 2004), Borneo (Ichikawa and Yasunari, 2006), and New Guinea (Ichikawa and Yasunari, 2008). The organisation of convection into mesoscale convective systems is also a strong function of the time of day, especially over the ocean (Nesbitt and Zipser, 2003). The diurnal cycle is further complicated by interactions with intraseasonal variability such as the Madden-Julian Oscillation (MJO; Tian et al., 2006; Ichikawa and Yasunari, 2006, 2007, 2008; Ho et al., 2008). Such scale interactions are an integral part of the convection, precipitation and circulation characteristics of the region (Sui and Lau, 1992; Mapes and Houze, 1993; Chen et al., 1996).

The spatial scales of the land-sea breezes and the scale interactions of convective organisation are much smaller than those resolved by climate models, which have a typical grid spacing of $200-400 \mathrm{~km}$. At this resolution, even the largest islands in the Maritime Continent are represented by only a few grid points. Hence, the lack of such processes in these models has been pinpointed as one of the major sources of error in their simulations (Yang and Slingo, 2001; Slingo et al., 2003). Even when the model resolution is increased by a factor of three, to a grid spacing of approximately $100 \mathrm{~km}$, there is no improvement in the simulation of precipitation over the maritime continent, or its associated global errors (Neale and Slingo, 2003).

The problem of inadequately resolving the land-sea distribution was highlighted further by Neale and Slingo (2003) in a sensitivity experiment. All the land points in the Maritime Continent were replaced by ocean. This led to a significant reduction in the dry bias, and an improvement in the global climate. When horizontal resolution is increased to $50 \mathrm{~km}$, improvements in the overall simulation of the diurnal cycle can be made (Ploshay and Lau, 2010). When horizontal resolution is increased sufficiently to resolve cloud systems and their scale interactions and selforganisation (grid spacing below $10 \mathrm{~km}$ ), a much more realistic simulation of maritime continent precipitation and its variability can be achieved (Miura et al., 2007; Sato et al., 2009). However, these model integrations are of higher resolution than those typically run operationally for numerical weather prediction (NWP), and much of higher resolution than those in long climate model integrations.

In this article, we assess the simulation of the diurnal cycle of precipitation over the Maritime Continent in the current version of the UK Met Office Unified Model (UM) as part of the Cascade project. Cascade aims to study scale interactions of tropical convection in large-domain, high-resolution model runs, with the aim of improving our understanding of how convection and convective parametrisation schemes interact with dynamics. The model is run as a limited-area model at three horizontal resolutions, with grid spacing of: (a) $40 \mathrm{~km}$, the same as that in the current operational global NWP model; (b) $12 \mathrm{~km}$, similar to that in the operational North Atlantic/Europe limited-area operational model; (c) $4 \mathrm{~km}$, similar to that in the UK domain limitedarea operational model. Convection was parametrised in the 40 and $12 \mathrm{~km}$ integrations. Convective parametrisation was switched on in the $4 \mathrm{~km}$ model but in practice almost all the convection was explicitly resolved. The effect of resolving the islands (land-sea distribution and topography) and of switching from parametrised to explicit convection on the amplitude and phasing of the diurnal cycle will be examined, including the effect on mean precipitation. In particular, the interactions between the diurnal land-sea breeze circulations and the offshore propagation of convection will be examined within a gravity wave framework.

\section{Model and data}

The UK Met Office UM, version 7.1, was used in the configuration described by Lean et al. (2008). This configuration applies a semi-implicit, semi-Lagrangian scheme to a rotated latitude-longitude grid (Davies et al., 2005) and applies parametrisations to represent boundarylayer turbulence (Lock et al., 2000), and mixed-phase microphysics (Wilson and Ballard, 1999). The model was configured for a limited-area integration over the tropical warm pool $\left(22^{\circ} \mathrm{S}\right.$ to $22^{\circ} \mathrm{N}, 40^{\circ} \mathrm{E}$ to $\left.183^{\circ} \mathrm{E}\right)$. Integrations were first carried out with two different horizontal grid spacings: $40 \mathrm{~km}$ and $12 \mathrm{~km}$. Each integration was run for the 2008-2009 northern winter season, from 11 October 2008 to 8 April 2009, giving 180 days from which to calculate the diurnal cycle. To accurately resolve the diurnal cycle, model diagnostics were output every hour. The initialisation and lateral boundary conditions were provided by interim reanalyses from the European Centre for Medium-range 


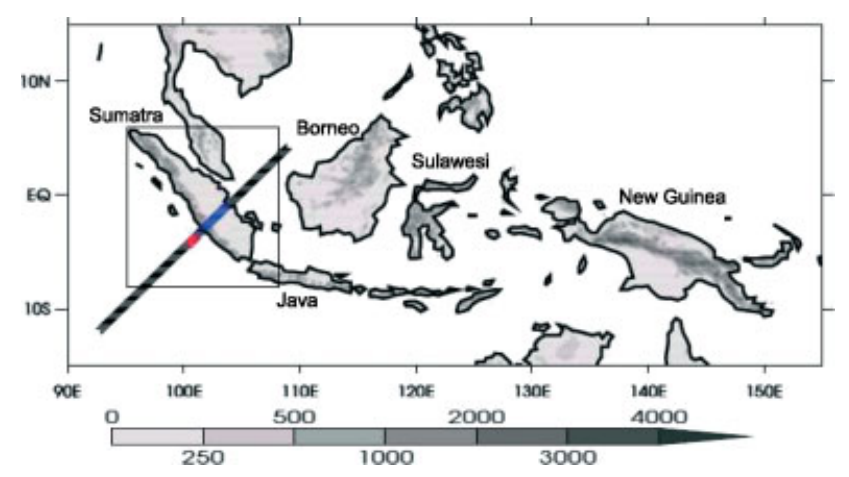

Figure 1. The topography of the warm pool domain $(\mathrm{m})$. The thick black line shows the section across Sumatra; the blue box shows the area used to diagnose the land-based convection, and the red box shows the area used to calculate the EOFs. The box around Sumatra shows the domain for the $4 \mathrm{~km}$ integration.

Weather Forecasts (ECMWF), with the lateral boundary conditions updated every $6 \mathrm{~h}$. A buffer zone of eight grid points was used to feed the lateral boundary conditions into the model. Hence, results are presented on two internal domains that are sufficiently far from these lateral boundary effects: (1) a 'full' warm pool domain $\left(15^{\circ} \mathrm{S}\right.$ to $15^{\circ} \mathrm{N}, 45^{\circ} \mathrm{E}$ to $\left.175^{\circ} \mathrm{E}\right),(2)$ a Maritime Continent subdomain $\left(15^{\circ} \mathrm{S}\right.$ to $15^{\circ} \mathrm{N}, 90^{\circ} \mathrm{E}$ to $155^{\circ} \mathrm{E}$, delineated in Figure 2).

Over the ocean, the model was forced by observed 20082009 SSTs which were updated every 30 days. The convective parametrisation uses a bulk plume model scheme with a CAPE* closure (Gregory and Rowntree, 1990). The $40 \mathrm{~km}$ model has a relative humidity dependence so that the CAPE closure time-scale is shortened when the column is moist. Consistent with operational procedure, the $12 \mathrm{~km}$ model does not have the relative humidity dependence; instead it has a vertical velocity dependence which reduces the CAPE closure time-scale when the vertical velocity is above a threshold. Both the $40 \mathrm{~km}$ and $12 \mathrm{~km}$ models were run with a 5 min time-step, 38 vertical levels and two-component microphysics (cloud liquid and frozen water).

A third integration was carried out over the island of Sumatra and surrounding seas $\left(8^{\circ} \mathrm{S}\right.$ to $6^{\circ} \mathrm{N}, 95^{\circ}$ to $107.5^{\circ} \mathrm{E}$; box in Figure 1), on a $4 \mathrm{~km}$ grid nested within the $12 \mathrm{~km}$ warm pool domain. Due to computational expense, this integration was only run for 60 days. Following operational procedure, the convective parametrisation scheme was enabled but the CAPE closure time-scale was increased at high values of CAPE, leading to very little parametrised convection. Hence, in practice almost all the convection was explicitly resolved. The $4 \mathrm{~km}$ model was run with a $30 \mathrm{~s}$ timestep, 70 vertical levels and three-component microphysics (as the $40 \mathrm{~km}$ model, plus prognostic rain).

Validation was by comparison with observed TRMM data. The TRMM 3B42 precipitation rate product (Huffman et al., 2007 ) is on a $0.25^{\circ}$ (approximately $28 \mathrm{~km}$ ) grid. The time resolution of the TRMM data was $3 \mathrm{~h}$, hence the hourly model data were averaged into $3 \mathrm{~h}$ means when a direct comparison was needed.

A mean diurnal cycle of a given variable was created by averaging all available data for a given time of day. Hence, for the 3-hourly TRMM data, eight mean maps were produced, at $0000,0300,0600,0900,1200,1500,1800$, and 2100 UTC.

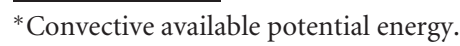

At each grid point, a curve of the form

$$
r=\bar{r}+A \cos \left\{\frac{2 \pi\left(t-t_{\phi}\right)}{24}\right\}
$$

was fitted, where $\bar{r}$ is the mean precipitation rate, $t$ is time in hours, and $A$ is the amplitude of the diurnal harmonic. The time of maximum precipitation $t_{\phi}$ was then converted from UTC to local solar time (LST) by subtracting $24 \lambda / 360$, where $\lambda$ is the longitude of the grid point. The diurnal cycle is presented as maps of $\bar{r}, A$ and $t_{\phi}$.

\section{Mean precipitation}

The observed mean precipitation rate $\bar{r}$ for the 2008-2009 northern winter season shows the broad maximum over the tropical warm pool, with the Intertropical Convergence Zone (ITCZ) along $5^{\circ} \mathrm{N}$ into the Pacific, and the South Pacific Convergence Zone (SPCZ) extending southeastward in the Southern Hemisphere (Figure 2(a)). Over the Maritime Continent there are notable precipitation maxima over Borneo, New Guinea and the Phillipines.

The corresponding precipitation map for the $40 \mathrm{~km}$ integration (Figure 2(b)) has similar overall features to the observations. However, there is more of a twin ITCZ structure over the Pacific, as the SPCZ is more zonally oriented in the model. This is a characteristic error of the UM at lower (climate) resolution, and of other climate models. Also, the oceanic precipitation in the $40 \mathrm{~km}$ model is too weak over the Maritime Continent, but precipitation over the islands is generally too strong. In particular, the model precipitation maxima are collocated with high topography, over the mountains of Sumatra, Borneo, Sulawesi and New Guinea. The deficit of oceanic precipitation is over a larger area than the excess land precipitation, giving a domain mean for the Maritime Continent of $5.2 \mathrm{~mm} \mathrm{day}^{-1}$ for the $40 \mathrm{~km}$ model. This is $1.7 \mathrm{~mm} \mathrm{day}^{-1}$ less than the TRMM observations $\left(6.9 \mathrm{~mm} \mathrm{day}^{-1}\right)$. Hence, the dry bias over the Maritime Continent that was a feature of the HadAM3 climate resolution model (Neale and Slingo, 2003) is still present in the $40 \mathrm{~km}$ model. In response to the dry bias, the climate model also had compensating equatorial wave or Walker circulations. These led to a precipitation excess over the western Indian Ocean and western Pacific. There is some evidence that these features are present in the $40 \mathrm{~km}$ model, particularly over the western Pacific. However, they do not compensate completely for the dry bias over the Maritime Continent, as the warm pool domain mean of $3.9 \mathrm{~mm} \mathrm{day}^{-1}$ is also less than the TRMM equivalent $\left(4.5 \mathrm{~mm}\right.$ day $\left.^{-1}\right)$.

The $12 \mathrm{~km}$ model shows a substantial improvement in the simulation of the mean precipitation (Figure 2(c)). The overall warm pool precipitation deficit of the $40 \mathrm{~km}$ model has been eliminated ( $12 \mathrm{~km}$ domain mean is $4.6 \mathrm{~mm}$ day $^{-1}$ compared to $4.5 \mathrm{~mm} \mathrm{day}^{-1}$ for TRMM). This is mainly due to an increase in oceanic precipitation over the Maritime Continent. However, there are still large systematic errors. The island precipitation maxima are still collocated with the mountain ranges. The overall precipitation deficit (dry bias) over the Maritime Continent still exists, although it is much reduced from the $40 \mathrm{~km}$ model (Maritime Continent domain mean is $6.9 \mathrm{~mm} \mathrm{day}^{-1}$ for TRMM, $6.3 \mathrm{~mm} \mathrm{day}^{-1}$ for $12 \mathrm{~km}$ model, $5.2 \mathrm{~mm} \mathrm{day}^{-1}$ for $40 \mathrm{~km}$ model). The dry bias in the $12 \mathrm{~km}$ model is now compensated for by precipitation excess over the western Indian Ocean and 

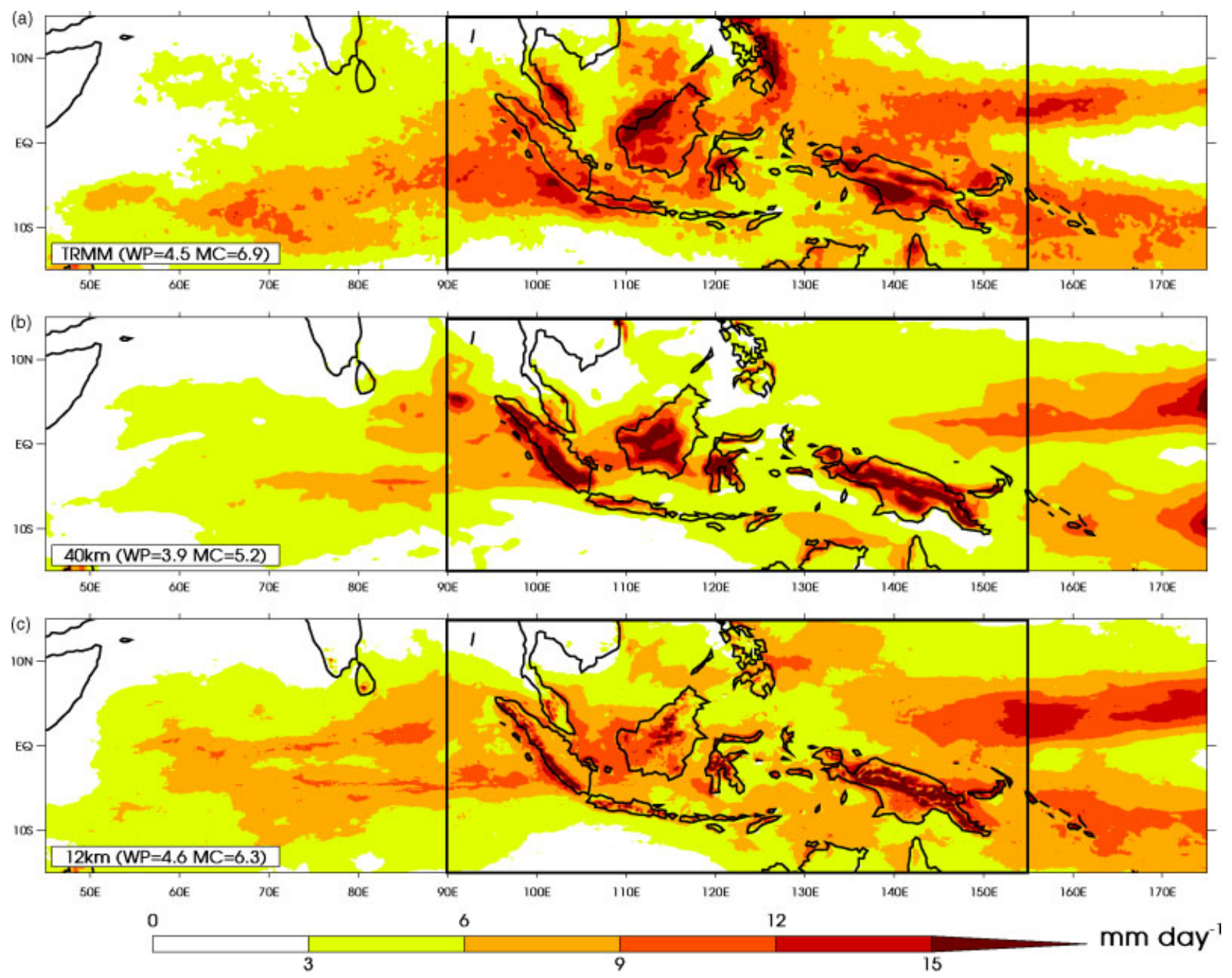

Figure 2. Daily mean precipitation rate $\bar{r}$ for northern winter 2008-2009 from (a) TRMM, (b) the $40 \mathrm{~km}$ model, and (c) the $12 \mathrm{~km}$ model, with contour interval $3 \mathrm{~mm}_{\text {day }}{ }^{-1}$. The thick black box delineates the Maritime Continent domain. The text box shows the mean precipitation rate averaged over the whole warm pool domain (WP) and the Maritime Continent domain (MC). This figure is available in colour online at wileyonlinelibrary.com/journal/qj

the western Pacific, as with the climate model (Neale and Slingo, 2003). Hence, although the warm pool domain mean in the $12 \mathrm{~km}$ model is realistic, it hides large spatial errors in local precipitation. The latent heating field associated with this erroneous precipitation would then force global circulation errors if fed into a global atmospheric model.

The precipitation from the 40 and $12 \mathrm{~km}$ models is almost entirely from the convective parametrisation scheme (less than $5 \%$ of the mean precipitation in these integrations is from explicitly resolved processes). In the $4 \mathrm{~km}$ integration almost all (99.9\%) of the precipitation is explicitly resolved. The mean precipitation field from the $4 \mathrm{~km}$ Sumatra integration (Figure 3(a)) shows a slight wet bias, with an area average of $11.8 \mathrm{~mm} \mathrm{day}^{-1}$, compared to 9.1 and $8.3 \mathrm{~mm} \mathrm{day}^{-1}$ for TRMM and the $40 \mathrm{~km}$ model, respectively, over the same Sumatran subdomain. Diagnostic analysis pointed to errors in the semi-Lagrangian advection scheme which does not formally conserve moisture. At this very high resolution, advection errors in regions of high moisture gradient lead to a source of moisture and the wet bias. Also, the initial conditions may be more unstable to convection as simulated in the $4 \mathrm{~km}$ model. There is then also a feedback with increased moisture inflow through the lateral boundary conditions of the limited-area model. Note that the maximum values of mean precipitation at individual grid points in the $4 \mathrm{~km}$ model greatly exceed those in the TRMM data or coarser resolution models (see the difference in shading levels between Figures 3(a) and 2). This is mainly due to the inherent smoothing on the coarser TRMM and 40 and $12 \mathrm{~km}$ model grids.

\section{Diurnal cycle over the Maritime Continent}

At 0900 LST, observed precipitation over the islands is weak (Figure $4(\mathrm{a})$ ), below $5 \mathrm{~mm} \mathrm{day}^{-1}$ in many regions. However, $12 \mathrm{~h}$ later, at $2100 \mathrm{LST}$, island precipitation is above $20 \mathrm{~mm} \mathrm{day}^{-1}$ in those same regions (Figure 4(b)). Conversely, precipitation over the oceans is generally weaker at 2100 than at 0900, particularly over the seas around the large islands. These two snapshots convey the primary importance of the diurnal cycle to precipitation over the Maritime Continent.

The amplitude of the diurnal cycle $(A)$ in observed precipitation over the Maritime Continent is largest over the islands and surrounding coastal seas (Figure 5(a)). It regularly exceeds $5 \mathrm{~mm} \mathrm{day}^{-1}$, in regions where the mean precipitation is approximately $10 \mathrm{~mm} \mathrm{day}^{-1}$. Hence the diurnal cycle represents a regularly repeating modulation of $50 \%$ of the mean precipitation. Over the open oceans, 

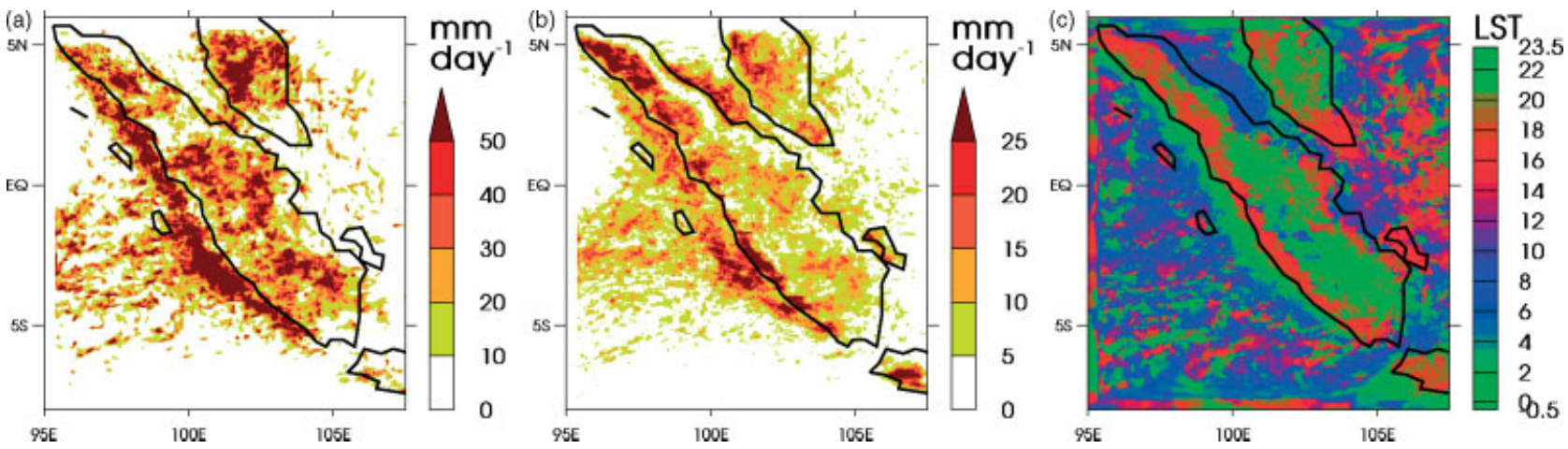

Figure 3. Precipitation rate for northern winter 2008-2009 from the $4 \mathrm{~km}$ model: (a) mean $\bar{r}$, (b) amplitude of the diurnal harmonic $A$, and (c) time of maximum precipitation in the diurnal harmonic $t_{\phi}$. The legends show the contour intervals (mm day ${ }^{-1}$ ) for (a) and (b), and the hour (LST) for (c).
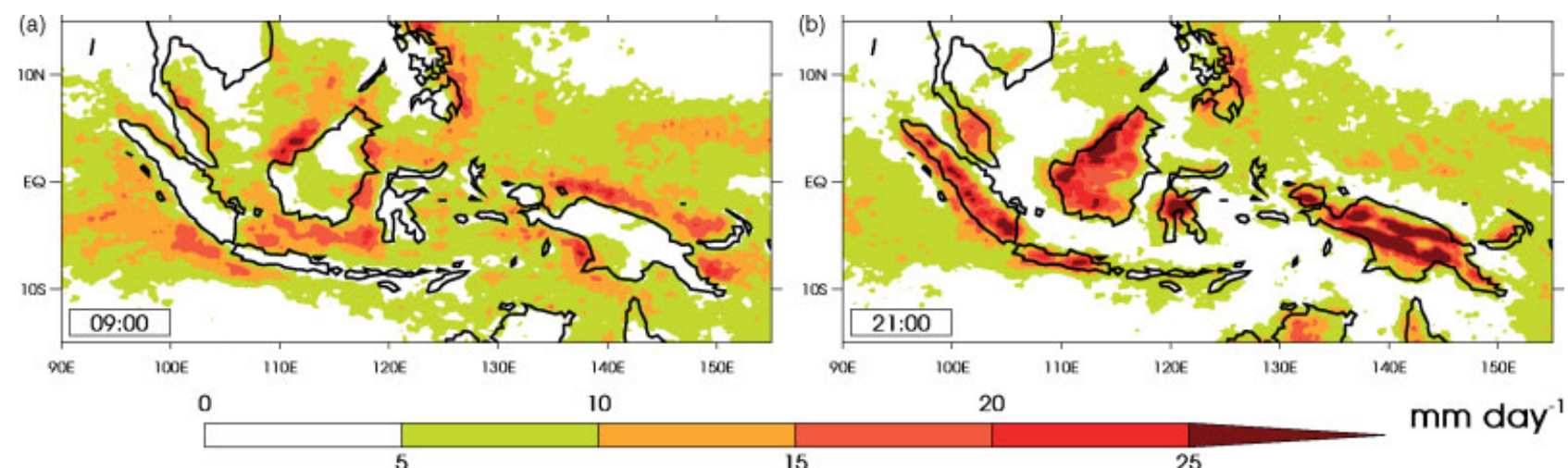

Figure 4. Mean precipitation rate $\bar{r}\left(\mathrm{~mm} \mathrm{day}^{-1}\right)$ for northern winter 2008-2009 from TRMM at (a) 0900 LST and (b) 2100 LST.

more than a few hundred kilometres from the large islands, the amplitude of the diurnal cycle is much smaller, typically $1 \mathrm{~mm} \mathrm{day}^{-1}$. In these regions the mean precipitation may still be $10 \mathrm{~mm} \mathrm{day}^{-1}$, hence the diurnal cycle is a modulation of only $10 \%$ of the mean. The phasing of the diurnal cycle is such that, over the land, the time of maximum precipitation is typically in the evening, whereas over the ocean it is in the morning (Figure 6(a)).

This general pattern is repeated in the $40 \mathrm{~km}$ model (Figure 5(b)). However, the amplitude of the diurnal cycle is weaker over the sea grid points, both over the open ocean and the coastal seas. The time of maximum precipitation over land is too early, around midday at the time of maximum solar heating. This error is common to many models (Yang and Slingo, 2001). It stems from the convective parametrisation scheme releasing instability as soon as it builds up, with no delay to allow for realistic mesoscale convective circulations to develop. Errors in the surface scheme (soil moisture and canopy evaporation) may also be a factor. In the $12 \mathrm{~km}$ model (not shown), the simulation is slightly improved, with a slightly stronger diurnal cycle over the open ocean. However, the weak diurnal cycle over the coastal seas is still present.

\subsection{Case-study: Sumatra}

We now focus on the details of the amplitude and phasing of the diurnal cycle over the individual islands. Sumatra is an especially suitable choice as it is essentially linear in shape, providing a relatively simple two-dimensional framework in which to examine the diurnal cycle. The observed diurnal cycle over Sumatra is a maximum just inland from the Barisan mountain range (Figure 5(a)) that runs northwest-southeast near the southwestern coastline (Figure 1). The convection peaks along the southwestern coastline in the evening (1800 LST; Figure 6(a)). Overnight, the precipitation then propagates both northeastward across Sumatra, and southwestward out over the Indian Ocean. By 0600 it has reached the Malacca Strait and the east coast of Sumatra, and the Mentawi Islands (the chain of islands off the southwest coast of Sumatra), respectively. This pattern is consistent with the propagating diurnal cycle identified by Mori et al. (2004), who also described the accompanying anomalies in wind, humidity and stability as part of a land-sea breeze circulation. The southwestward propagation continues coherently out into the Indian Ocean throughout the morning, eventually becoming incoherent at a distance of approximately $800 \mathrm{~km}$ from the Sumatran coast. This limit approximately coincides with the point at which the amplitude of the diurnal cycle drops below $1 \mathrm{~mm} \mathrm{day}^{-1}$ (Figure 5(a)). Note that the phasing of the diurnal cycle becomes noisy and incoherent outside this 'envelope' of active diurnal activity, taken as the approximate limit of the $1 \mathrm{~mm} \mathrm{day}^{-1}$ contour of the amplitude of the diurnal harmonic in Figure 5(a). This is due to sampling errors from synoptic systems that swamp the weak diurnal signal.

The propagation speeds can be estimated from a Hovmöller diagram of precipitation (Figure 7(a)) along the southwest-northeast section across Sumatra shown by the thick line in Figure 1. The northeastward propagation from the island centre at $102^{\circ} \mathrm{E}$ to the Malacca Strait is at $8 \mathrm{~m} \mathrm{~s}^{-1}$. The southwestward propagation into the Indian Ocean has a slightly slower phase speed of $7 \mathrm{~m} \mathrm{~s}^{-1}$ to $99^{\circ} \mathrm{E}$, where it merges into a standing oscillation in precipitation 

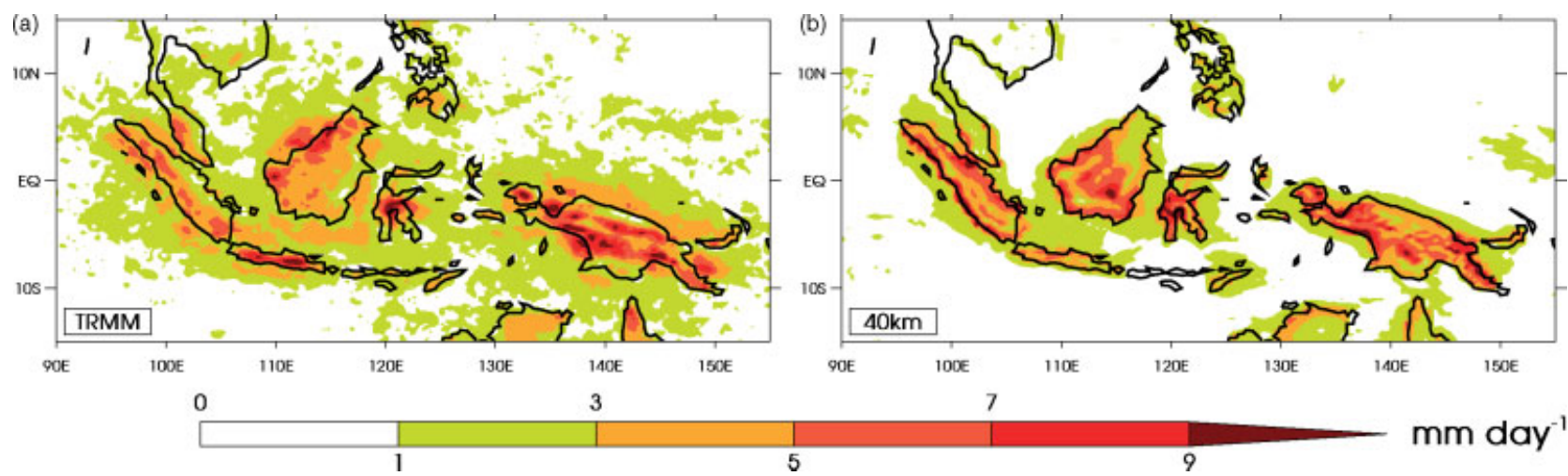

Figure 5. Amplitude of the diurnal harmonic $A$ of precipitation rate $\left(\mathrm{mm} \mathrm{day}^{-1}\right)$ from (a) TRMM and (b) the $40 \mathrm{~km}$ model.
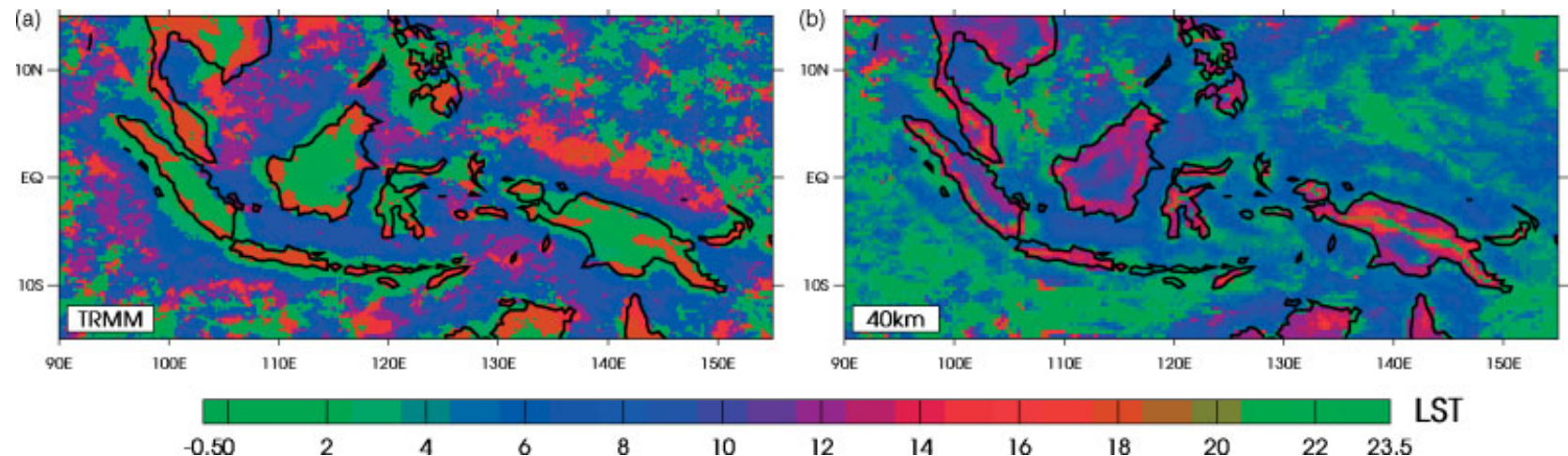

Figure 6. Time of maximum precipitation (local solar time) of the diurnal harmonic $t_{\phi}$ of precipitation rate from (a) TRMM and (b) the $40 \mathrm{~km}$ model. The shading interval is $1 \mathrm{~h}$.

over the open ocean that peaks at 0600 LST. This standing oscillation can be identified as the open ocean diurnal cycle (Woolnough et al., 2004).

The $40 \mathrm{~km}$ model partly captures this pattern. However, the maximum amplitude of the diurnal cycle is around the Sumatran coastline, rather than inland (Figure 5(b)). The phasing of the peak precipitation is located correctly over the western coast at 1800 LST (Figure 6(b)). However, it then propagates northeastward over inland Sumatra much slower than observed, only reaching the northeast coast at 1200 LST the next day, at which point coherent propagation stops. The net effect here is that precipitation in the model over the island peaks much earlier in the day than in the observations. Propagation southwestward into the Indian Ocean is also weaker than in the TRMM observations, and only reaches just beyond the line of the Mentawi Islands. This is also consistent with the envelope of diurnal activity, i.e. the $1 \mathrm{~mm} \mathrm{day}^{-1}$ contour of the amplitude of the diurnal harmonic only extending this far from the island in the $40 \mathrm{~km}$ integration (Figure 5(b)). There is also a strong standing oscillation over the Sumatra land grid points in the $40 \mathrm{~km}$ model, with a precipitation maximum tied to the solar heating and peaking around noon (1200 LST; Figure $7(\mathrm{~b})$ ). The combination of the propagating and standing components leads to two maxima per day over the centre of the island $\left(102.5^{\circ} \mathrm{E}\right.$ in Figure $\left.7(\mathrm{~b})\right)$. Because of these differences, it is difficult to identify and calculate propagation speeds southwestward into the Indian Ocean and northeastward over the island in the $40 \mathrm{~km}$ model from the Hovmöller diagram (Figure 7(b)). However, although the propagation is weaker and slower in the $40 \mathrm{~km}$ model than in observations, this is a great improvement on climate resolution simulations of the UM, where no such clear diurnal cycle and offshore propagation were present (Neale and Slingo, 2003).

The general characteristics of the convection and its diurnal cycle can be seen from a Hovmöller diagram of raw precipitation data along the Sumatra section, for 30 days starting from 11 October 2008 (Figure 8). In the TRMM observations (Figure $8(\mathrm{a})$ ), the general picture is of synoptic weather systems propagating westwards across Sumatra, which are modulated by the diurnal cycle. There is low-frequency modulation of the synoptic and diurnal cycle, with a burst of activity from 18 October 2008 to 23 October (days 8-13), followed by a quiescent period until 1 November 2008 (day 21), then a second burst of activity to the end of the period. This westward synoptic propagation and low-frequency modulation is distinctly absent in the $40 \mathrm{~km}$ model (Figure 8(b)). Here the precipitation is dominated by a strong diurnal cycle that is anchored to the land area of Sumatra, with much weaker propagation offshore.

The amplitude, phasing and general character of the diurnal cycle in the $12 \mathrm{~km}$ model (not shown) are similar to those in the $40 \mathrm{~km}$ model. Hence, the increase in resolution here does not appear to have a significant effect on the diurnal cycle.

In the $4 \mathrm{~km}$ model, with explicit convection, the maximum amplitude of the diurnal cycle tends to have two maxima, one running along the Barisan mountain chain and the other parallel to the coast, approximately $50 \mathrm{~km}$ offshore, between the southwest coast and the Mentawi Islands (Figure 3(b)). This is similar to observations (Figure 5(a)), whereas in the 
$40 \mathrm{~km}$ model there is a single maximum runnning around the coastline (Figure 5(b)). Additionally, the timings of peak precipitation over Sumatra (Figure 3(c)) match the timing of the TRMM observations well (Figure 6(a)). Overall, the $4 \mathrm{~km}$ model does generate both the southwestward and northeastward propagation from the coastal mountain range (Figure 7(c)) as seen in the TRMM observations (Figure 7(a)) and described by Mori et al. (2004). Estimated phase speeds are 3 and $5 \mathrm{~m} \mathrm{~s}^{-1}$, respectively, which are slower than observed. In addition, the envelope of diurnal convective activity does not extend as far offshore as is observed. Furthermore, whilst the $4 \mathrm{~km}$ model retains a distinct diurnal cycle, it is not dominated by the diurnal cycle in solar radiation as in the $40 \mathrm{~km}$ model (Figure 8(b)). Rather, it displays behaviour similar to the TRMM observations and shows propagating synoptic weather systems modulated by the diurnal cycle (Figure 8(c)).

\subsection{Diurnal heating over land and offshore gravity wave propagation}

The diurnal cycle of offshore propagation of convection over the Maritime Continent is linked to strong diurnal heating over the land, and associated land-sea breeze circulations and gravity wave propagation (e.g. Yang and Slingo, 2001; Mapes et al., 2003). These interactions are now examined first in the $40 \mathrm{~km}$ model. Four hours after sunrise, at 1000 LST, deep convection has already begun over the island. The vertical profile of the temperature increment from the convective parametrisation scheme over the island at 1000 LST (Figure 9(a)) shows deep heating throughout the troposphere. The pronounced minimum at $4000 \mathrm{~m}$ is due to the melting of falling hydrometeors. The associated profile of anomalous temperature at 1000 LST over the island (Figure 9(b)) is the cumulative response to the heating over the previous few hours. It also shows a deep tropospheric warm anomaly. This deep warm anomaly over the island can also be seen in a vertical slice along the Sumatra section at 1000 LST (Figure 10(a)), along with the associated deep ascent.

This triggers a 'deep' gravity wave adjustment process, with the positive temperature anomalies beginning to spread or propagate outwards, to the left (southwest) and right (northeast). The anomalous descent at the leading edge of these gravity waves leads to adiabatic warming and provides the physical mechanism by which the temperature anomaly is redistributed horizontally (diabatic heating is negligible offshore). The smooth decrease in the amplitude of the descent and positive temperature anomaly with distance offshore reflects the gradual ramping up of the island convection from sunrise. At sufficiently far enough distances from the island $\left(97.5^{\circ} \mathrm{E}\right.$ and $\left.108.5^{\circ} \mathrm{E}\right)$, there is no positive temperature anomaly, as the gravity waves forced at sunrise over the island have not yet reached these points by 1000 LST.

By 1300 LST, one hour after maximum solar heating, the island convection is well established and the positive temperature anomalies have strengthened and reached further offshore. The associated sea-breeze circulation is clearly evident, with strong, concentrated ascent over the island, offshore flow in the upper troposphere (above $6000 \mathrm{~m}$ ), weaker, diffuse descent offshore, and onshore flow below $6000 \mathrm{~m}$ (Figure 10(b)).

Mori et al. (2004) documented the transition from convective-type to stratiform-type precipitation during
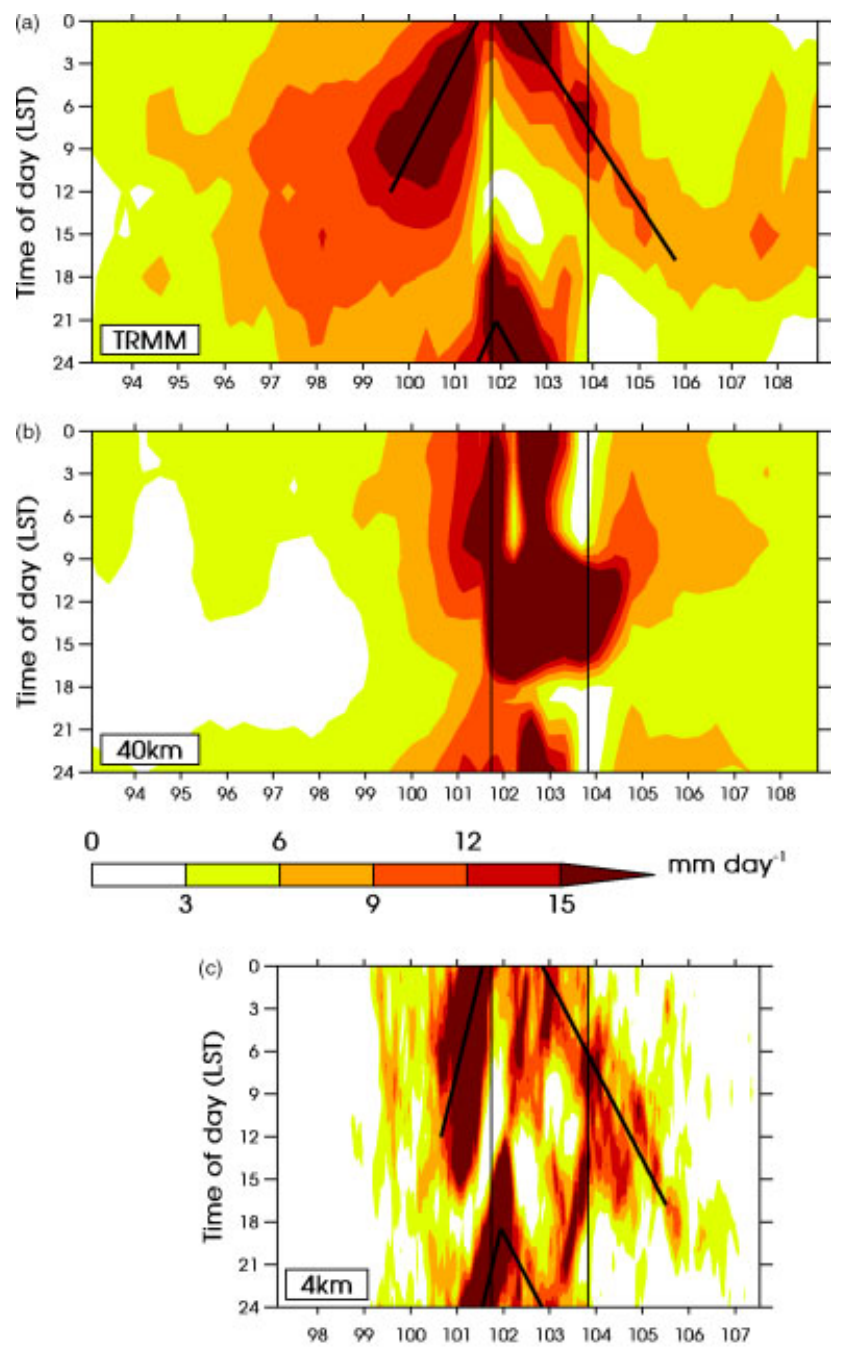

0

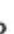

24

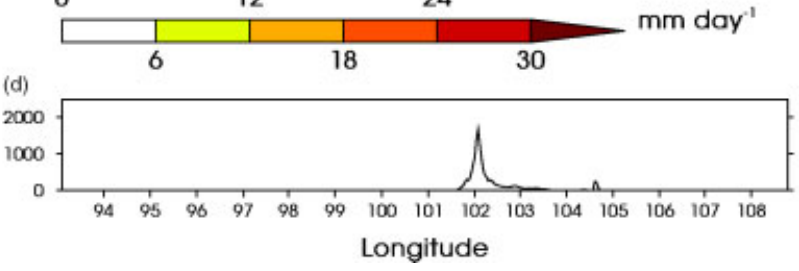

Figure 7. Hovmöller diagram of the diurnal cycle of precipitation rate along the Sumatran cross-section in Figure 1, for (a) TRMM, (b) the $40 \mathrm{~km}$ model and (c) the $4 \mathrm{~km}$ model. The legends show the shading levels $\left(\mathrm{mm} \mathrm{day}^{-1}\right)$. The vertical lines at $101.7^{\circ} \mathrm{E}$ and $103.8^{\circ} \mathrm{E}$ indicate the Sumatran coastline. Diagonal lines indicate propagation. (d) indicates the orography (m) along the Sumatra cross-section. This figure is available in colour online at wileyonlinelibrary.com/journal/qj

the day over Sumatra from observations. This transition will be accompanied by a change in the vertical heating profile, with the convective precipitation having a single mid-tropospheric maximum, and the stratiform precipitation comprising upper tropospheric heating and mid-tropospheric cooling (Houze, 1997). The $40 \mathrm{~km}$ model captures this transition. By 1300 LST, cloud systems have matured and become more stratiform. Hence, the heating profile over the island changes, with a more top-heavy profile at 1300 LST, and a more accentuated minimum at $4000 \mathrm{~m}$ (black dashed line in Figure 9(a)). The temperature response over the island mimics this (black dashed line in Figure 9(b)). This change in the heating profile will then force a different combination of vertical gravity wave modes. This is evident 
(a)

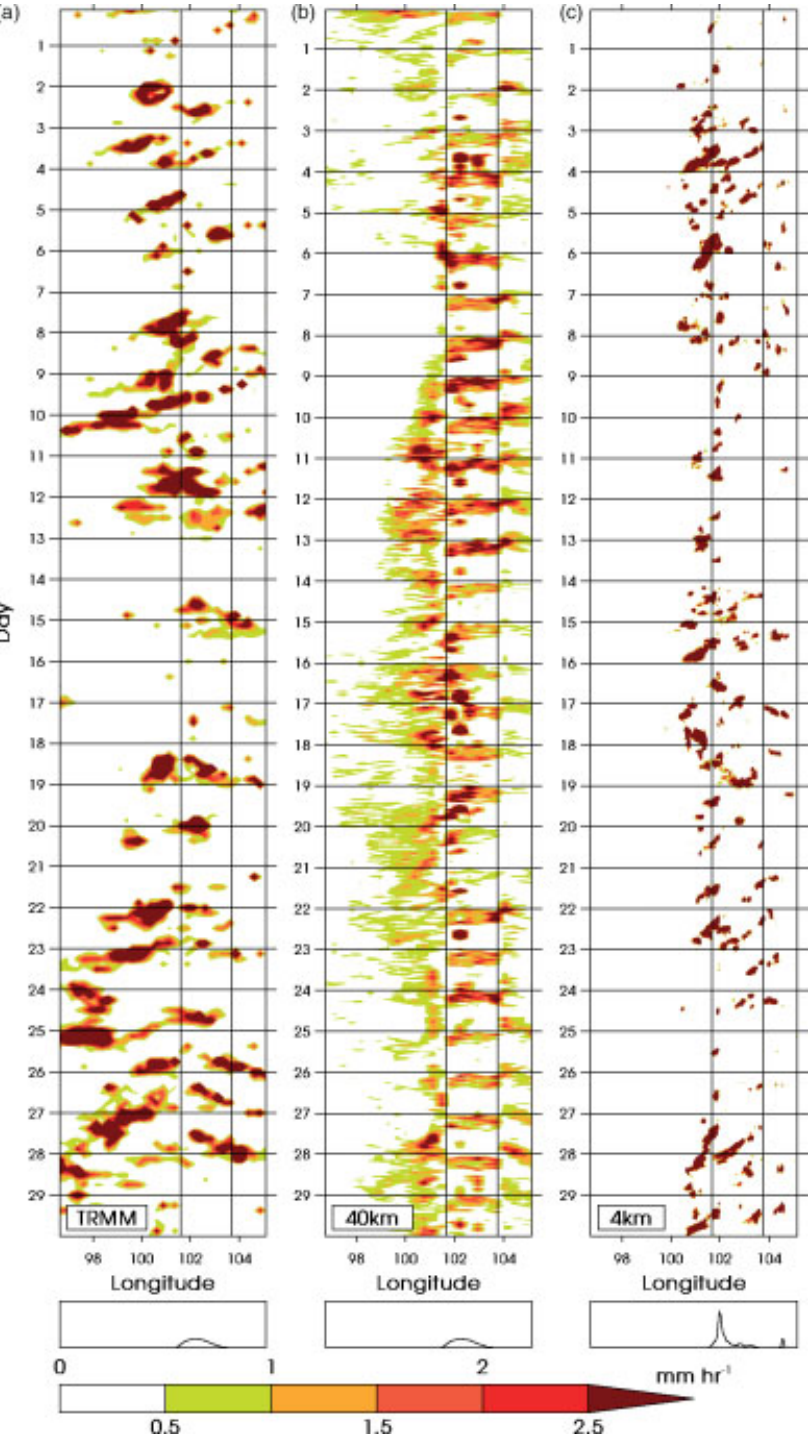

Figure 8. Hovmöller diagram of precipitation rate along the Sumatra section for the 30-day period from 11 October 2008 for (a) TRMM, (b) the $40 \mathrm{~km}$ model and (c) the $4 \mathrm{~km}$ model. The legend shows the shading levels $\left(\mathrm{mm} \mathrm{hr}^{-1}\right)$. The vertical lines at $101.7^{\circ} \mathrm{E}$ and $103.8^{\circ} \mathrm{E}$ indicate the Sumatran coastline and the lower panels show the orography.

by 1600 LST (Figure 10(c)), when a new vertical structure is evident over the island, with a more pronounced maximum at $12000 \mathrm{~m}$, a negative temperature anomaly at $5000 \mathrm{~m}$, and a positive temperature anomaly below (Figures 9(b),10(c)).

The higher-order gravity wave mode then propagates offshore both ways, at $100.5^{\circ} \mathrm{E}$ and $104.5^{\circ} \mathrm{E}$ by 1900 LST (Figure $10(\mathrm{~d})$ ). A more complex circulation profile is associated with this mode; there is offshore flow below $4000 \mathrm{~m}$, onshore flow between 6000 and $11000 \mathrm{~m}$, and offshore flow above $12000 \mathrm{~m}$. To complete mass conservation, the leading edge of this mode ( e.g. at $99^{\circ} \mathrm{E}$ at 1900 LST, Figure $10(\mathrm{~d})$ ) has ascent at $5000 \mathrm{~m}$. Adiabatic cooling from this ascent is the physical mechanism leading to the cold anomaly at $5000 \mathrm{~m}$.

By 2200 LST, this higher-order gravity wave mode has spread further offshore (Figure 10(e)). Note that the leading edge of this wave (at $99^{\circ} \mathrm{E}$ at $1900 \mathrm{LST}$, and $94^{\circ} \mathrm{E}$ at 2200 LST) has near-surface convergence, between the near-surface offshore flow from the higher-order gravity wave and the near-surface onshore flow from the trailing edge of the deeper gravity wave. This convergence (a)
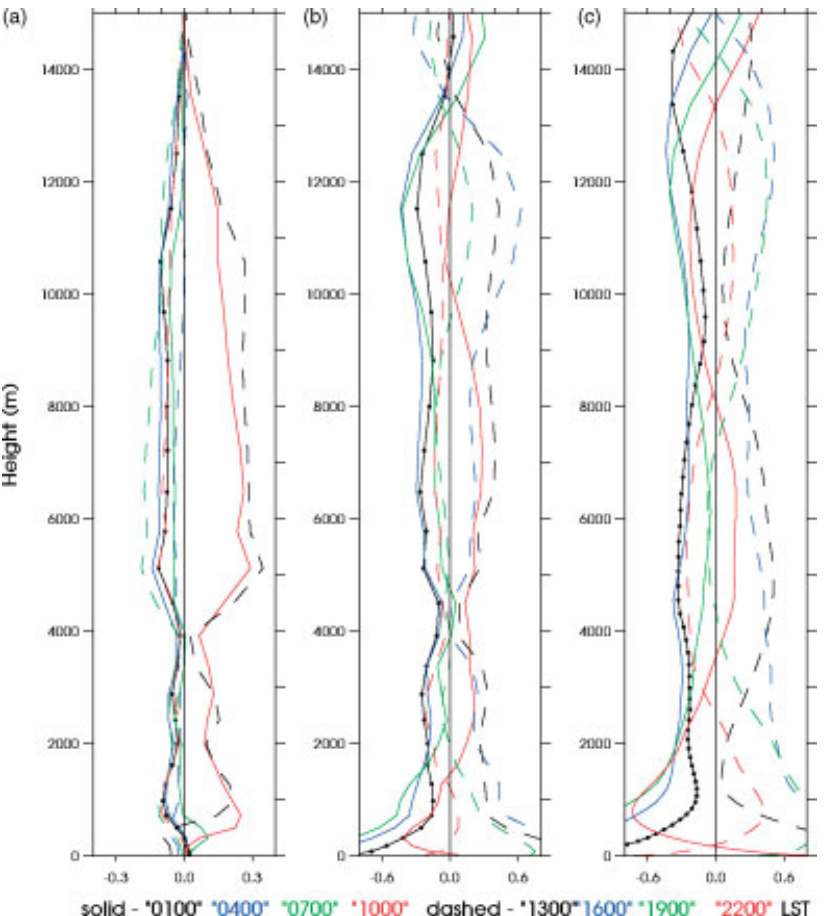

Figure 9. Diurnal cycle, averaged over the land points in the Sumatran section, of the vertical profile of (a) diabatic heating (temperature increment from convection: $\mathrm{Kh}^{-1}$ ) from the $40 \mathrm{~km}$ model, (b) temperature anomaly (K) from the $40 \mathrm{~km}$ model, (c) temperature anomaly (K) from the $4 \mathrm{~km}$ model.

zone between the gravity wave modes will then favour convection over the ocean (Mapes, 1993), as will the destabilising cold anomaly at $5000 \mathrm{~m}$ in the higher-order gravity wave.

\subsection{Objective analysis of gravity wave modes}

Hence, the change in heating profile over Sumatra during the day leads to a change in the make-up of the offshore gravity wave response. To objectively quantify this response, and simplify the analysis, an empirical orthogonal function (EOF) analysis was performed on the diurnal cycle of the temperature profile at a representative offshore location on the Sumatran section, a box centred at $100.0^{\circ} \mathrm{E}, 4.8^{\circ} \mathrm{S}$. For the $40 \mathrm{~km}$ model, the first two EOFs accounted for $98 \%$ of the variance. EOF1 (79\% of the variance; solid line in Figure 11(b)) has a deep structure with positive temperature anomalies throughout the troposphere. This is the structure identified as the deep gravity wave mode from Figure 10 that propagated offshore during the day. EOF2 (19\% of the variance; dashed line in Figure 11(b)) can be identified as the higher-order gravity wave that propagated offshore in the early evening.

Note that the exact levels of the peaks in heating and cooling over the islands do not quite match the levels of maximum and minimum temperature anomalies of the offshore gravity waves. For example, the minimum in island heating is at $4000 \mathrm{~m}$ (black dashed line in Figure 9(a)), but the minimum temperature anomaly in EOF2 is at $5000 \mathrm{~m}$ (black dashed line in Figure 11(b)). This can be explained by the island topography, which elevates the heating. The vertical coordinate is height above ground. If a typical Sumatran topographic height of $1000 \mathrm{~m}$ is added to the heating profiles, they then closely match the gravity wave 

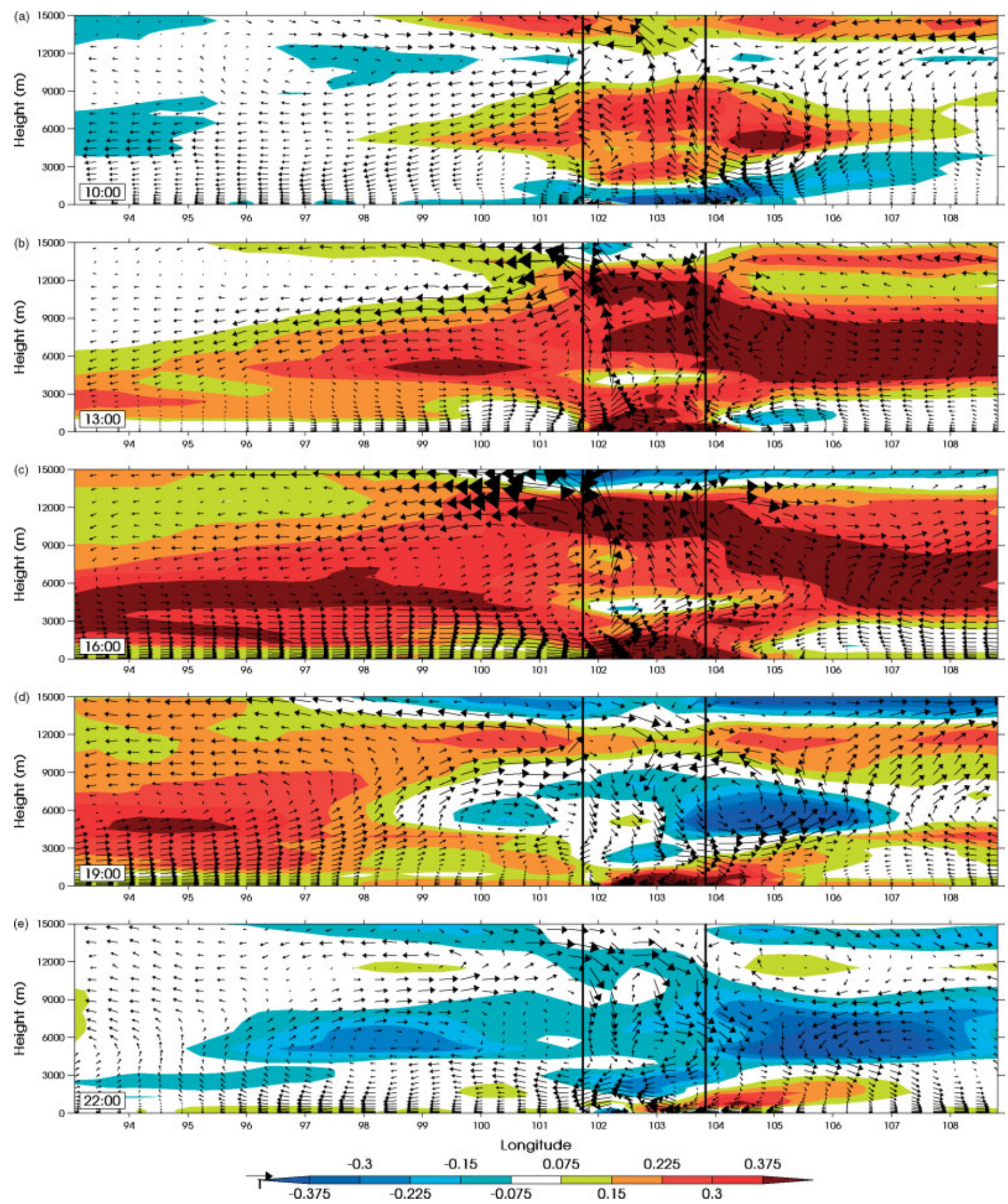

Figure 10. Vertical slices along the Sumatra section of the diurnal cycle of anomalous temperature (shading), along-section horizontal wind and vertical wind (vectors), at (a) 1000, (b) 1300, (c) 1600, (d) 1900, (e) $2200 \mathrm{LST}$, for the $40 \mathrm{~km}$ model. The vertical lines at $101.7^{\circ} \mathrm{E}$ and $103.8^{\circ} \mathrm{E}$ indicate the Sumatran coastline.

structures over the ocean. A similar result was found for the diurnal cycle of heating and offshore gravity waves off South America (Mapes et al., 2003).

An EOF analysis of the vertical heating profile of the $40 \mathrm{~km}$ model was carried out for the island box, to quantify the change in heating profile throughout the day. The leading two EOFs accounted for $99 \%$ of the variance. EOF1 (94\% of the variance, solid line in Figure 11(a)) has a deep structure like EOF1 of the $40 \mathrm{~km}$ temperature profile, with positive anomalies throughout the troposphere and a peak at $5000 \mathrm{~m}$. EOF2 (5\% of the variance, dotted line Figure 11(a)) has a more complex structure with a negative peak at $4000 \mathrm{~m}$ and a prominent positive peak beween $9000 \mathrm{~m}$ and $12000 \mathrm{~m}$. These two EOFs represent convective and stratiform heating respectively and together they describe the diurnal transition from mid-tropospheric convective 

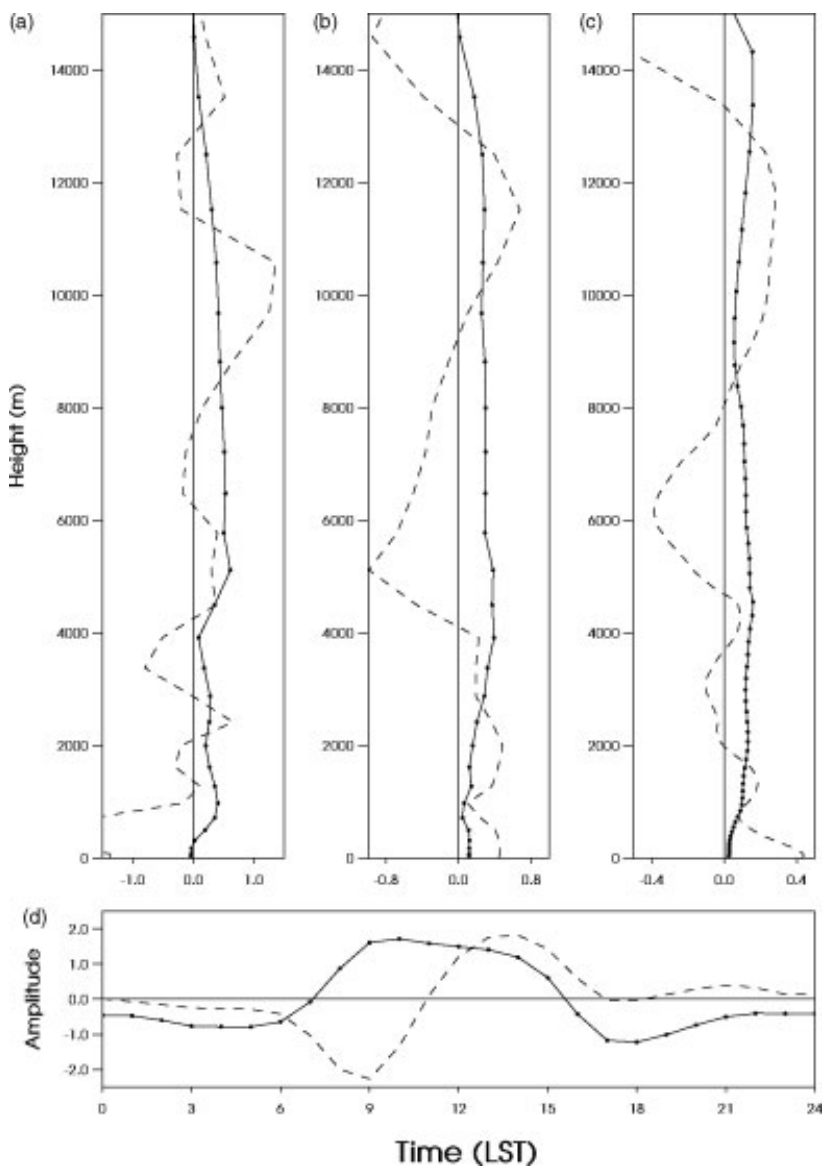

Figure 11. Vertical profiles of the leading two EOFs of the diurnal cycl of (a) diabatic heating (temperature increment from convection: $\mathrm{K} \mathrm{h}^{-1}$ ) averaged over the land points in the Sumatran section from the $40 \mathrm{~km}$ model, (b) temperature (K) in the offshore box for the $40 \mathrm{~km}$ model, and (c) temperature $(\mathrm{K})$ in the offshore box for the $4 \mathrm{~km}$ model. EOF1 is shown by the solid lines, and EOF2 by the dashed lines. (d) Principal component time series of the amplitudes of EOF1 (solid line) and EOF2 (dashed line) of the heating profile in (a).

heating to upper-tropospheric stratiform heating and midtropospheric cooling. This is illustrated by the principal component time series of the EOFs (Figure 11(d)). The convective heating (solid line) has a clear diurnal cycle that peaks at 1000 LST, while the stratiform heating (dashed line) peaks three hours later at 1300 LST. While the separation of convective and stratiform heating is similar to that identified in observations (Mori et al., 2004), Figure 11(d) illustrates that the peak in convection in the $40 \mathrm{~km}$ model occurs too early, by approximately $6 \mathrm{~h}$.

The relevance of these gravity wave structures to the maritime continent as a whole is now assessed. Each EOF structure was projected back onto the diurnal cycle of temperature profiles to produce a principal component (PC) time series, giving the temporal evolution of the amplitude of the EOF at the base grid box. This PC time series is dominated by the diurnal harmonic, from which the amplitude and phase (time of maximum) can be calculated. This procedure can then be repeated at every grid box over the Maritime Continent to produce maps of the amplitude and phase of the diurnal harmonic of each EOF (Figure 12).

The diurnal harmonic of the deep gravity wave represented by EOF1 has a high amplitude over all the islands of the Maritime Continent (Figure 12(a)). Its amplitude is also high over the surrounding oceans, but decreases steadily with distance from land. The phase, or time of maximum, is approximately 1500 LST over the large islands (Sumatra, New Guinea), becoming later (1600 to 1700 LST) with distance from land (Figure 12(c)). This is consistent with forcing of the gravity wave by convection over land, then rapid propagation offshore. The implied fast phase speed is consistent with the deep vertical structure of this gravity wave.

EOF2, which represents the higher-order gravity wave, also has a high amplitude over the islands (Figure 12(b)). The time of maximum over the islands is 1600 to 1700 LST (Figure 12(d)), slightly later than for EOF1. The amplitude of EOF2 decreases, and the time of maximum becomes later, at a much higher rate with distance from land, when compared with EOF1. Hence, the higher-order gravity wave of EOF2 propagates much more slowly and is more confined to the coastal area than the deep mode of EOF1. In particular, the slow offshore propagation and diminution can be seen radiating out from the coasts of Sumatra, Borneo and New Guinea. Overall, these EOF structures and their diurnal cycle describe a coherent picture of the land-sea breeze circulations over the entire Maritime Continent in the $40 \mathrm{~km}$ model.

The phase speed of the deep gravity mode can be estimated as approximately $60 \mathrm{~m} \mathrm{~s}^{-1}$ from a Hovmöller diagram of PC1 along the Sumatra section (Figure 13(a)). Haertel et al. (2008) calculated the theoretical vertical structures and phase speeds for linear gravity waves in the Tropics. They assumed a resting atmosphere with a mean stratification taken from the TOGA-COARE ${ }^{\dagger}$ soundings in the western Pacific, and rigid boundaries at the surface $(1000 \mathrm{hPa})$ and tropopause $(100 \mathrm{hPa})$. Under these conditions, the theoretical first internal gravity wave mode had a one-signed temperature structure, very similar to the deep gravity wave here, and a phase speed of $52 \mathrm{~m} \mathrm{~s}^{-1}$. Given the assumptions in their model, this is consistent with the phase speed found for the one-signed EOF1 (solid line in Figure 11(b)) gravity wave here.

Note that the offshore propagation appears to become a standing oscillation (infinite phase speed) far from the coast (far left of Figure 13(a)). As well as capturing the deep, offshore-propagating gravity wave, the EOF1 temperature structure also projects onto the vertical structure of the 'open ocean' diurnal cycle. This open ocean cycle is a forced response to the westward-propagating solar forcing. At the southwest end of the Sumatra section $\left(94^{\circ} \mathrm{E}\right)$, this open ocean diurnal cycle begins to dominate, and the diurnal cycle becomes a fixed standing oscillation, when displayed in local solar time. It has a maximum at 1800 LST, and a minimum at 0600 LST, consistent with the aquaplanet experiments of Woolnough et al. (2004).

The higher-order gravity wave (EOF2; dashed line in Figure 11(b)) has three sign reversals, i.e. it is the fourth internal mode. From Figure 13(b), its phase speed is estimated at $31 \mathrm{~m} \mathrm{~s}^{-1}$.

\subsection{Impact of gravity waves on offshore precipitation}

The two gravity waves, which are forced by the changing vertical profile of heating over the land, propagate offshore and can then impact the offshore convection and

\footnotetext{
${ }^{\dagger}$ Tropical Ocean-Global Atmosphere Coupled Ocean-Atmosphere Response Experiment
} 

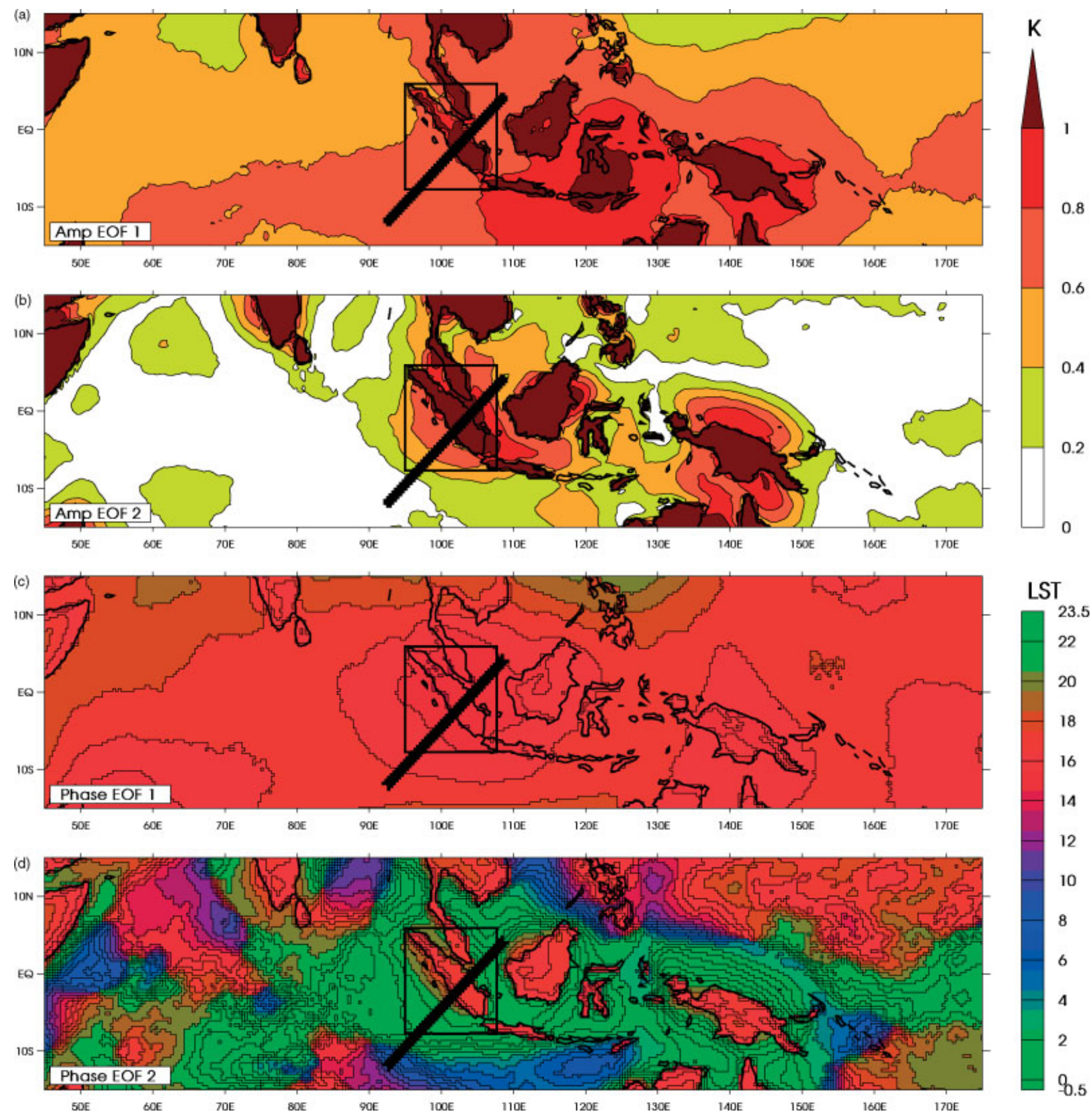

Figure 12. Amplitude $A$ of the diurnal harmonic of the PC time series of (a) EOF1, (b) EOF2 of temperature in the offshore box, from the $40 \mathrm{~km}$ model. Time of maximum $t_{\phi}$ (LST) of the diurnal harmonic of (c) EOF1, (d) EOF2.

precipitation. The adiabatic cooling from their ascending wavefronts, and adiabatic warming from the descending wavefronts, will change the temperature profile of the offshore atmosphere, modifying its stability to convection. The diurnal evolution of the deep gravity wave (PC1) along the Sumatran section in the $40 \mathrm{~km}$ model is shown in the Hovmöller diagram of Figure 13(a). Selected contours of precipitation rate are also shown in Figure 13(a); the full Hovmöller diagram of precipitation rate appears in Figure $7(\mathrm{~b})$. The precipitation peaks near midday and its associated latent heat release forces the positive, warm (i.e. downwelling) phase of the deep gravity wave (PC1) to propagate offshore during the afternoon. The positive temperature anomalies of this gravity wave (solid line in Figure 11(b)) will stabilise the atmosphere and suppress convection offshore. This is consistent with the minimum in offshore precipitation seen in the model during this time (Figure 13(a)). As the precipitation becomes more stratiform and the vertical heating profile over the land changes during the afternoon (Figure 9(a)), the positive phase of the fourth internal mode gravity wave (PC2) is excited. This propagates slowly offshore in the late afternoon (Figure 13(b)). The negative temperature anomaly of this mode at $5000 \mathrm{~m}$ (dashed line in Figure $11(\mathrm{~b})$, at $100.5^{\circ} \mathrm{E}$ in Figure 10(d)) will tend to destabilise the atmosphere and enhance convection. Consistent with this forcing, precipitation does develop and propagate offshore, towards the left of the section, immediately after the destabilising gravity wave has passed through. However, the subsequent propagation speed of the precipitation anomaly is much slower than the gravity wave. 

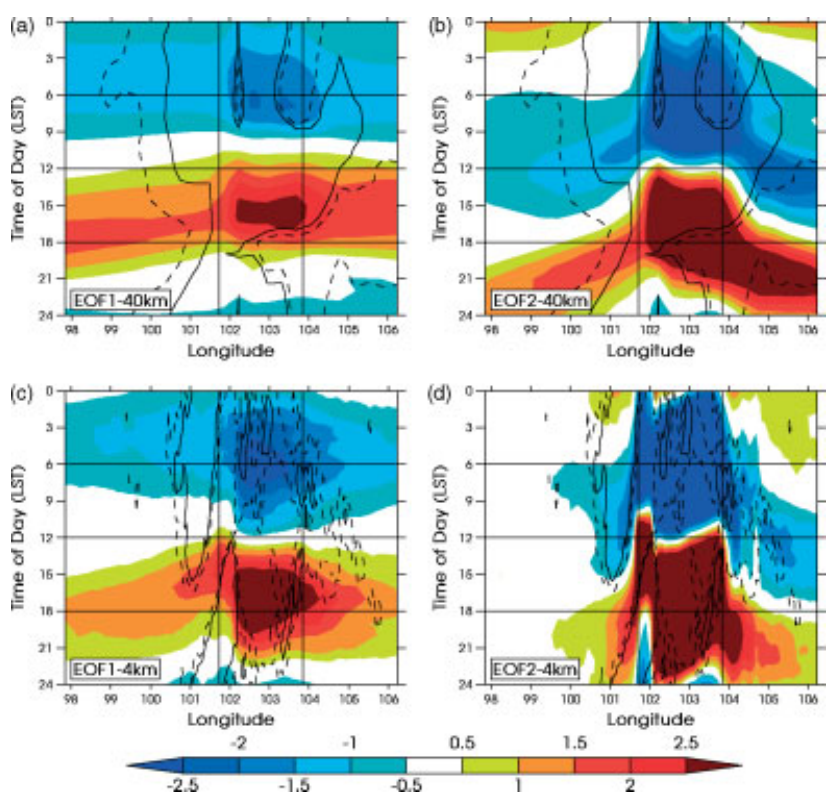

Figure 13. Hovmöller diagrams of the diurnal cycle along the Sumatra section in the $40 \mathrm{~km}$ model of PC time series of temperature (a) EOF1 and (b) EOF2 (shading). Selected contours of precipitation rate from Figure 7 are also plotted. The vertical lines at $101.7^{\circ} \mathrm{E}$ and $103.8^{\circ} \mathrm{E}$ indicate the Sumatran coastline. (c)-(d) are as (a)-(b), but for the $4 \mathrm{~km}$ model.

\subsection{Explicit convection ( $4 \mathrm{~km}$ model)}

In contrast to the $40 \mathrm{~km}$ model, the propagating gravity wave in the $4 \mathrm{~km}$ model exerts a much more direct control on the offshore propagation of precipitation in the diurnal cycle. Note that there is no diurnal cycle of the convective forcing or temperature increment from convection (equivalent of Figure 9(a)), as the convection in the $4 \mathrm{~km}$ model is explicitly resolved. However, the evolution of the temperature profiles over the island box for the $4 \mathrm{~km}$ model is still indicative of the (explicitly resolved) convective forcing. The diurnal cycle of heating is more realistic in the $4 \mathrm{~km}$ model, with the peak warming occuring in the late afternoon, rather than being tied to the solar maximum at $1200 \mathrm{LST}$ as in the $40 \mathrm{~km}$ model. When compared to the $40 \mathrm{~km}$ convectively parametrised model in Figure 9(b), the heating profile from the $4 \mathrm{~km}$ explicit convection model exhibits a more pronounced shift from a mid-tropospheric $(5000 \mathrm{~m})$ maximum at $1300 \mathrm{LST}$, indicative of convective rain, to a distinctly top-heavy profile with a maximum at $12000 \mathrm{~m}$, at 1900 LST, indicative of stratiform rain. The difference in the evolution of the landbased heating profile then leads to differences in the offshore gravity wave response.

The EOF analysis of the diurnal cycle of the temperature profile over the offshore box was repeated for the $4 \mathrm{~km}$ model. Again, the leading two EOFs accounted for the bulk (95\%) of the variance. EOF1 (solid line in Figure 11(c); $82 \%$ of the variance) has a similar one-signed structure to EOF1 from the $40 \mathrm{~km}$ model (solid line in Figure 11(c)), and is also identified as the first internal mode gravity wave. It is excited in the early afternoon by the diurnal heating over Sumatra and then propagates rapidly offshore at approximately $40 \mathrm{~m} \mathrm{~s}^{-1}$ (to the left in Figure 13(c)). As with the $40 \mathrm{~km}$ model, the positive temperature anomalies associated with this gravity wave stabilise the atmosphere and shut off the offshore precipitation in the early afternoon.

The second EOF (dashed line in Figure 11(c); 13\% of the variance) has many similarities with its counterpart from the $40 \mathrm{~km}$ model (dashed line in Figure 11(c)), with positive temperature anomalies in the upper troposphere, and negative anomalies in the middle troposphere. However, the structure in the lower to mid-troposphere is more complex, with three crossing points, and this represents a higher-order vertical mode than in the $40 \mathrm{~km}$ model. This is consistent with the slower propagation speed once the gravity wave has been excited in the late afternoon (Figure 13(d)), compared to its counterpart in the $40 \mathrm{~km}$ model (Figure 13(b)).

However, there is also an additional qualitative difference between the two models. The offshore propagation of precipitation appears to be directly triggered by the higher vertical mode gravity wave. The positive phase of the higherorder gravity wave mode (with its destabilising negative temperature anomaly in the mid-troposphere) is triggered in the mid-afternoon by a change of heating profile over the island. It propagates offshore during the early evening and is immediately followed by offshore propagation of precipitation, at a similar phase speed (Figure 13(d)). Similarly, during the morning, the propagation of the negative (stabilising) phase of the gravity wave is closely followed by the cessation (trailing edge) of the offshore precipitation.

\section{Discussion and conclusions}

The atmospheric component of the UK Met Office UM is known to have a significant dry bias over the Maritime Continent when run at climate resolution. This has been traced to a deficient representation of the diurnal cycle of convection. To investigate this problem, and the mechanisms behind the diurnal cycle, the model has been run here at three (higher) resolutions: 40,12 , and $4 \mathrm{~km}$, as part of the Cascade project. The mean precipitation over the Maritime Continent still exhibited a dry bias in the $40 \mathrm{~km}$ model, similar to that in the climate model. When the model resolution was increased $(12 \mathrm{~km})$, the mean precipitation over the Maritime Continent was much improved, but this still masked significant regional errors (too wet over land, too dry over the ocean). When the model resolution was increased further, to $4 \mathrm{~km}$, the convection became explicitly resolved; the convective parametrisation scheme accounted for over $95 \%$ of precipitation in the 40 and $12 \mathrm{~km}$ models, but less than $0.1 \%$ in the $4 \mathrm{~km}$ model. The $4 \mathrm{~km}$ model also exhibited a systematic bias in precipitation, with the mean now being too high. This arises because moisture is not conserved by the semi-Lagrangian advection scheme when the model is run at very high resolution.

At $40 \mathrm{~km}$ resolution, the same as the operational global NWP model, the model simulates many realistic attributes of the observed diurnal cycle. The amplitude of the diurnal cycle over the islands and seas are realistic. The model has a tendency for too strong a diurnal cycle over the islands, which is too closely tied geographically to the coastlines and high mountains and peaks too early, around midday. Over the ocean, the amplitude of the diurnal cycle is too weak. However, this is a significant improvement in the diurnal cycle over the Maritime Continent to that when the model is run at climate (approximately $300 \mathrm{~km}$ ) resolution. The diurnal cycle in the $12 \mathrm{~km}$ model was qualitatively similar, so the further increase in resolution did not appear to lead to a significant improvement in the diurnal cycle. However, 
when the resolution was increased to $4 \mathrm{~km}$, with explicit convection, the phasing of the diurnal cycle was much improved on the coarser-resolution models. The qualitative character of the precipitation features in the $4 \mathrm{~km}$ model were similar to observations, with westward propagating synoptic features interacting loosely with the fixed diurnal cycle, whose amplitude varied from day to day. In contrast, the 40 and $12 \mathrm{~km}$ models exhibited a much more regular behaviour, with the diurnal cycle repeating almost every day, and relatively little synoptic activity.

The diurnal cycle in offshore convection was analysed in a framework of propagating gravity waves, forced by the landbased convection, precipitation and latent heat release. In particular, a comparison was made between the behaviour in the $40 \mathrm{~km}$ model with convective parametrisation, and the $4 \mathrm{~km}$ model with explicit convection. In both models, the heating profile over the islands changed from a convective profile, with maximum heating in the mid-troposphere during the early afternoon, to a profile with more of a stratiform component (upper-tropospheric heating and mid-tropospheric cooling) later in the day. This is consistent with observations of the diurnal cycle (e.g. Houze, 1997; Mori et al., 2004).

This change in the heating profile then excited two gravity wave modes that propagated away from the coast. Each mode was preferentially forced at a different time of day, and then propagated with a different phase speed. The two modes, their vertical structure, and propagation characteristics were identified objectively using an EOF analysis.

The deep convective heating forced a first internal mode gravity wave, with a one-signed temperature anomaly throughout the troposphere. This downwelling gravity wave propagated rapidly offshore at $60 \mathrm{~m} \mathrm{~s}^{-1}$ during the early afternoon. The adiabatic warming from the passage of the gravity wave stabilised the atmosphere, suppressing convection offshore at this time. The stratiform heating component later in the afternoon forced a higher-order vertical mode gravity wave. The exact details of this mode's vertical structure differed between the models, particularly in the lower troposphere, due to the differing heating profiles from the parametrised and explicit convection. However, in both models this mode propagated slowly, and had a negative temperature anomaly in the lower troposphere that destabilised the column and promoted convection. Additionally, a region of low-level convergence propagated offshore, between the wave fronts of the two gravity waves. This will also favour convection (Mapes, 1993).

The convective response to this destabilising influence differs between the two models. In the parametrised $40 \mathrm{~km}$ model, the convective enhancement offshore does follow the destabilising passage of the gravity wave, but the convection itself then propagates offshore at a slower phase speed. In the explicit $4 \mathrm{~km}$ model, the convective response is tied much more tightly to the destabilising gravity wave, becoming phase-locked to it and propagating at the same speed. It is only in the $4 \mathrm{~km}$ model, with explicit convection and a strong convective response to gravity wave forcing, that the propagation of convection, southwestward over the Indian Ocean and northeastward over the island, is correctly simulated when compared to observations (diagonal lines in Figure $7(\mathrm{a}, \mathrm{c})$ ). This provides a strong argument for the role of diurnally forced gravity waves in the diurnal cycle of convection over the maritime continent. The propagation of the higher-order gravity wave, forced by the stratiform convection, is the crucial element in controlling the offshore propagation of convection. The timing of this wave is governed by the timing of the transition from convective to stratiform behaviour over the islands, and the propagation speed of this wave is governed by the details of the heating profile of the stratiform component. Hence, the correct representation and simulation of these two elements are important model development goals. Further detailed analysis of the switch from convective to stratiform heating from observations over the islands is also needed to validate the model simulations.

Furthermore, given that the offshore propagating precipitation is so closely tied to the offshore propagating gravity wave, the latent heat release from the precipitation may feed back onto the gravity wave. Such 'convective coupling' has been observed between convection and largescale equatorial waves in the tropics (Wheeler and Kiladis, 1999) and may be operating on the smaller scales here. Latent heat release from condensation and precipitation in the ascending part of the wave reduces the effective static stability, slowing the wave speed. Hence, this could be a factor in the reduced propagation speed of the high-order gravity wave in the $4 \mathrm{~km}$ model, compared to the $40 \mathrm{~km}$ model.

Given that the offshore propagation of the two gravity wave modes is well represented in both models, but the phasing of the diurnal cycle of propagating offshore convection is more accurate in the $4 \mathrm{~km}$ model with explicit convection, then the apparent relative insensitivity of the convective parametrisation scheme in the $40 \mathrm{~km}$ model to these gravity wave structures appears to be an important component of this model's error. In particular, sensitivity to mid-tropospheric temperature destabilisation over the ocean, by the higher-order gravity wave response to stratiform heating over land, should be addressed.

These errors in the precipitation over the Maritime Continent, and their subsequent effect on global circulation through planetary wave propagation, are a major source of global systematic model error. Hence, given that global forecast models are typically run at $40 \mathrm{~km}$ resolution, with the need for convective parametrisation (and climate models are run at much coarser resolution), then the sensitivity of convection to gravity wave propagation is likely to be a promising area for parametrisation development.

\section{Acknowledgements}

The TRMM 3B42 data were obtained from NASA-Goddard DAAC, from their website at http://disc.gsfc.nasa.gov/services/opendap/

We thank Steve Woolnough and Chris Holloway for their comments on the manuscript and helpful discussions. We thank two anonymous reviewers for their helpful tips and input.

BSL and GMSL were supported by the Natural Environment Research Council through the Cascade project (NE/E003885/1 and NE/E00525X/1).

\section{References}

Chen SS, Houze RA, Mapes BE. 1996. Multiscale variability of deep convection in relation to large-scale circulation in TOGA-COARE. J. Atmos. Sci. 53: 1380-1409. 
Davies T, Cullen MJP, Malcolm AJ, Mawson MH, Staniforth A, White AA, Wood N. 2005. A new dynamical core for the Met Office's global and regional modelling of the atmosphere. Q. J. R. Meteorol. Soc. 131: 1759-1782.

Gregory D, Rowntree PR. 1990. A mass flux convection scheme with the representation of cloud ensemble characteristics and stabilitydependent closure. Mon. Weather Rev. 118: 1483-1506.

Haertel PT, Kiladis GN, Denno A, Rickenbach TM. 2008. Vertical-mode decompositions of two-day waves and the Madden-Julian Oscillation. J. Atmos. Sci. 65: 813-833.

Ho CH, Park MS, Choi YS, Takayabu YN. 2008. Relationship between intraseasonal oscillation and diurnal variation of summer rainfal over the South China Sea. Geophys. Res. Lett. 35: L03701. DOI: 10.1029/2007GL031962.

Houghton JT, Ding Y, Griggs DJ, Noguer M, van der Linden PJ, Dai X, Maskell K, Johnson CA. (eds.) 2001. Climate change 2001: The scientific basis. Contribution of Working Group I to the Third Assessment Report of the Intergovernmental Panel on Climate Change. Cambridge University Press: Cambridge, UK.

Houze RA. 1997. Stratiform precipitation in regions of convection: A meteorological paradox? Bull. Amer. Meteorol. Soc. 78: 2179-2196.

Huffman GJ, Adler RF, Bolvin DT, Gu GJ, Nelkin EJ, Bowman KP, Hoong Y, Stocker EF, Wolff DB. 2007. The TRMM multisatellite precipitation analysis (TMPA): Quasi-global, multiyear, combinedsensor precipitation estimates at fine scales. J. Hydrometeorol. 8: $38-55$.

Ichikawa H, Yasunari T. 2006. Time-space characteristics of diurnal rainfall over Borneo and surrounding oceans as observed by TRMMPR. J. Climate 19: 1238-1260.

Ichikawa H, Yasunari T. 2007. Propagating diurnal disturbances embedded in the Madden-Julian Oscillation. Geophys. Res. Lett. 34: L18811. DOI: 10.1029/2007GL030480.

Ichikawa H, Yasunari T. 2008. Intraseasonal variability in diurnal rainfall over New Guinea and the surrounding oceans during austral summer. J. Climate 21: 2852-2868.

Jin F-F, Hoskins BJ. 1995. The direct response to heating in a baroclinic atmosphere. J. Atmos. Sci. 52: 307-319.

Lean HW, Clark PA, Dixon M, Roberts NM, Fitch A, Forbes R, Halliwell C. 2008. Characteristics of high-resolution versions of the Met Office Unified Model for forecasting convection over the United Kingdom. Mon. Weather Rev. 136: 3408-3434.

Lock AP, Brown AR, Bush MR, Martin GM, Smith RNB. 2000. A new boundary-layer mixing scheme. Part I: Scheme description and single-column model tests. Mon. Weather Rev. 128: 3187-3199.

Mapes BE. 1993. Gregarious tropical convection. J. Atmos. Sci. 50: 2026-2037.
Mapes BE, Houze RA. 1993. Cloud clusters and superclusters over the oceanic warm pool. Mon. Weather Rev. 121: 1398-1415.

Mapes BE, Warner TT, Xu M. 2003. Diurnal patterns of rainfall in northwestern South America. Part III: Diurnal gravity waves and nocturnal convection offshore. Mon. Weather Rev. 131: $830-844$.

Miura H, Satoh M, Nasuno T, Noda AT, Oouchi K. 2007. A Madden-Julian Oscillation event realistically simulated by a global cloud-resolving model. Science 318: 1763-1765.

Mori S, Hamada JI, Tauhid YI, Yamanaka MD, Okamato N, Murata F, Sakurai N, Hashiguchi H, Sribimawati T. 2004. Diurnal land-sea rainfall peak migration over Sumatera Island, Indonesian Maritime Continent, observed by TRMM satellite and intensive rawinsonde soundings. Mon. Weather Rev. 132: 2021-2039.

Neale RB, Slingo JM. 2003. The Maritime Continent and its role in the global climate: A GCM study. J. Climate 16: 834-848.

Nesbitt SW, Zipser EJ. 2003. The diurnal cycle of rainfall and convective intensity according to three years of TRMM measurements. J. Climate 16: $1456-1475$.

Ploshay JJ, Lau N-C. 2010. Simulation of the diurnal cycle in tropical rainfall and circulation during boreal summer with a high-resolution GCM. Mon. Weather Rev. 138: 3434-3453.

Sato T, Miura H, Satoh M, Takayabu YN, Wang Y. 2009. Diurnal cycle of precipitation in the tropics simulated in a global cloud-resolving model. J. Climate 22: 48090-4826.

Slingo JM, Inness PM, Neale RB, Woolnough SJ, Yang GY. 2003. Scale interactions on diurnal to seasonal timescales and their relevance to model systematic errors. Annales Geophys. 46: 139-155.

Sui CH, Lau KM. 1992. Multiscale phenomena in the tropical atmosphere over the western Pacific. Mon. Weather Rev. 120: 407-430.

Tian B, Waliser DE, Fetzer EJ, Lambrigtsen BH, Yung YL, Wang B. 2006. Vertical moist thermodynamic structure and spatial-temporal evolution of the MJO in AIRS observations. J. Atmos. Sci. 63: 2462-2485.

Wheeler M, Kiladis GN. 1999. Convectively coupled equatorial waves: Analysis of clouds and temperature in the wavenumber-frequency domain. J. Atmos. Sci. 56: 374-399.

Wilson DR, Ballard SP. 1999. A microphysically based precipitation scheme for the UK Meteorological Office Unified Model. Q. J. R. Meteorol. Soc. 125: 1607-1636.

Woolnough SJ, Slingo JM, Hoskins BJ. 2004. The diurnal cycle of convection and atmospheric tides in an aquaplanet GCM. J. Atmos. Sci. 61: 2559-2573.

Yang GY, Slingo JM. 2001. The diurnal cycle in the Tropics. Mon. Weather Rev. 129: 784-801. 